\title{
Rudolf Holbach, Michel Pauly (dir.), Städtische Wirtschaft im Mittelalter
}

Köln, Weimar, Wien : Böhlau, 2011, 374 p., 52,90€

\section{Olivier Richard}

\author{
(2) OpenEdition \\ Journals \\ Édition électronique \\ URL : http://journals.openedition.org/ifha/7529 \\ DOI : 10.4000/ifha.7529 \\ ISSN : 2198-8943 \\ Éditeur \\ IFRA - Institut franco-allemand (sciences historiques et sociales) \\ Référence électronique \\ Olivier Richard, "Rudolf Holbach, Michel Pauly (dir.), Städtische Wirtschaft im Mittelalter », Revue de \\ I'IFHA [En ligne], Date de recension, mis en ligne le 13 décembre 2013, consulté le 22 septembre 2020. \\ URL : http://journals.openedition.org/ifha/7529 ; DOI : https://doi.org/10.4000/ifha.7529
}

Ce document a été généré automatiquement le 22 septembre 2020.

(CIFHA 


\title{
Rudolf Holbach, Michel Pauly (dir.), Städtische Wirtschaft im Mittelalter
}

Köln, Weimar, Wien : Böhlau, 2011, 374 p., 52,90€

\author{
Olivier Richard
}

Franz Irsigler s'est fait un nom comme spécialiste de l'économie urbaine, de Trèves, où il était professeur, ou encore comme fin connaisseur de l'économie de la ville de Cologne au Moyen. C'est pourquoi il se voit honoré par ce volume d'hommage consacré à l'économie urbaine au Moyen Âge, auquel participent treize auteur(e)s de huit pays différents. Comme toujours pour ce genre d'ouvrages, les thèmes et les espaces abordés sont très divers. Josef Žemlicka décrit le commerce de Prague vers l'Occident au Moyen Âge haut et central, Jean-Luc Fray s'intéresse à l'économie urbaine en moyenne montagne, à partir des villes du Massif Central; en insistant sur les relations nombreuses avec l'extérieur, il balaie le cliché de l'isolement et insiste sur l'urbanité, notamment des bâtiments, dans les villes même de petite taille. Francesca Bocchi consacre son article aux places publiques de l'Italie communale (XIII ${ }^{\mathrm{e}}-\mathrm{XIV}{ }^{\mathrm{e}} \mathrm{s}$.), et Rosa Smurra à l'hôtel de ville de Bologne et ses parties commerciales à la même époque. Roman Czaja porte un jugement nuancé, sur le commerce prussien au tournant du Xve siècle, avec des différences fortes selon les lieux et les secteurs d'activité. Hans-Jörg Gilomen étudie une pratique mal connue et pourtant très fréquente à la fin du Moyen Âge, l'achat à crédit, d'après les exemples de Bâle et Zurich. Il conclut que cette forme de crédit se substitua en partie au prêt à intérêt, dans toutes les couches de la société ; il accompagne son article de l'édition de la liste des débiteurs d'un épicier (Krämer) bâlois. Deux articles sont d'abord des réflexions sur des sources de types particuliers: Volker Henn évoque les contrats d'engagement, les statuts de métier et les serments des apothicaires, ainsi que les listes de prix des médicaments (Arzneitaxen); il montre que les villes s'attachaient à réglementer très strictement leur activité, en particulier par le biais des médecins, et son étude relativise beaucoup la thèse du fossé Nord-Sud défendue dans les travaux plus anciens en histoire de la pharmacie dans l'Empire. Ferdinand Opll présente l'histoire et le contenu du fonds, conservé à Vienne, des archives d'un légat pontifical de la seconde moitié $d u x^{e}$ siècle, l'évêque Alexandre de 
Forlì, et suggère ce qu'il peut apporter à l'histoire religieuse, politique et économique de son époque.

Michel Pauly et Martin Uhrmacher dessinent l'aire d'approvisionnement de la ville de Luxembourg, en partant d'abord aux différents produits. Ils essaient ensuite d'en présenter un croquis de synthèse, mi-carte mi-graphique, en quatre zones concentriques : c'est un bel exemple de la cartographie comme outil heuristique pour l'histoire. Rudolf Holbach traite de la production textile entre Meuse et Rhin, en se penchant en particulier sur le statut des tisserands de Boppard (près de Coblence), datant de la fin du XIV $v^{e}$ ou du début du XV siècle (qu'il édite et traduit en annexe). Knut Schulz étudie les métiers de la métallurgie autour de Steyr en Autriche: les mines, l'extension géographique de la production, les liens avec les autorités seigneuriales, enfin la coutellerie et la production de faux. Harald Witthöft se penche sur les salines de Lunebourg du Moyen Âge à l'époque moderne, pour lesquelles il fait une petite étude de métrologie; il ne se contente cependant pas de convertir les anciennes mesures, mais propose une petite histoire culturelle des poids et mesures. Enfin le volume se clôt sur un stimulant essai d'histoire globale, où Carl-Hans Hauptmeyer, dans une « coupe longitudinale » de l'économie urbaine, soutient que la ville médiévale peut encore faire fonction de modèle pour les réflexions actuelles sur la ville.

Avec des interrogations sur le commerce, la production artisanale, la topographie de l'économie urbaine, les rapports entre l'économie urbaine et les seigneurs, ce volume de mélanges offre un panorama bien sûr incomplet, mais tout de même varié des recherches sur l'économie urbaine médiévale de l'Empire, provenant en majorité d'auteurs proches de la génération de Franz Irsigler lui-même ; il est enrichi d'éditions de sources en annexe et, dans plusieurs cas, d'un appareil cartographique très utile. L'ouvrage fait honneur à son dédicataire.

INDEX

Index chronologique : Mittelalter

Thèmes : Regionale Geschichte/ Stadtgeschichte, Wirtschaftsgeschichte

\section{AUTEUR}

OLIVIER RICHARD

Université de Haute-Alsace, Mulhouse 